\title{
UHPLC-MS/MS Analysis on Flavonoids Composition in Astragalus membranaceus and Their Antioxidant Activity
}

\author{
Zhili Sheng ${ }^{1,2}$, Yueming Jiang ${ }^{1,3} \mathbb{C}^{\text {, Junmei Liu }}{ }^{2}$ and Bao Yang ${ }^{1,3, *}$ \\ 1 Guangdong Provincial Key Laboratory of Applied Botany, South China Botanical Garden, \\ Chinese Academy of Sciences, Guangzhou 510650, China; shengzl@scbg.ac.cn (Z.S.); ymjiang@scbg.ac.cn (Y.J.) \\ 2 College of Food Science and Engineering, Jilin Agricultural University, Changchun 130118, China; \\ spring430817@163.com \\ 3 University of Chinese Academy of Sciences, Beijing 100049, China \\ * Correspondence: yangbao@scbg.ac.cn; Tel.: +86-20-3708-3042
}

check for updates

Citation: Sheng, Z.; Jiang, Y.; Liu, J.; Yang, B. UHPLC-MS/MS Analysis on Flavonoids Composition in Astragalus membranaceus and Their Antioxidant Activity. Antioxidants 2021, 10, 1852. https://doi.org/10.3390/ antiox10111852

Academic Editor: Gwonhwa Song

Received: 26 October 2021

Accepted: 18 November 2021

Published: 22 November 2021

Publisher's Note: MDPI stays neutral with regard to jurisdictional claims in published maps and institutional affiliations.

Copyright: (c) 2021 by the authors. Licensee MDPI, Basel, Switzerland. This article is an open access article distributed under the terms and conditions of the Creative Commons Attribution (CC BY) license (https:// creativecommons.org/licenses/by/ $4.0 /)$.

\begin{abstract}
Astragalus membranaceus is a valuable medicinal plant species widely distributed in Asia. Its root is the main medicinal tissue rich in methoxylated flavonoids. Origin can highly influence the chemical composition and bioactivity. To characterize the principal chemicals influenced by origin and provide more information about their antioxidant profile, the extracts of $A$. membranaceus roots from four origins were analysed by UHPLC-MS/MS. Thirty-four flavonoids, including thirteen methoxylated flavonoids, fifteen flavonoid glycosides and six flavonols, were identified. By principal component analysis, eighteen identified compounds were considered to be principal compounds. They could be used to differentiate A. membranaceus from Shanxi, Inner Mongolia, Heilongjiang and Gansu. The antioxidant activity was analysed by ORAC assay, DPPH radical scavenging activity assay and cell antioxidant activity assay. 'Inner Mongolia' extract showed the highest antioxidant activity. These results were helpful to understand how origin influenced the quality of A. membranaceus.
\end{abstract}

Keywords: antioxidant activity; ORAC; origin; phenolics; principal component analysis

\section{Introduction}

Astragalus membranaceus (Fabaceae) is a well-known traditional Chinese herbal medicine, which is mainly distributed in Asian regions [1]. The root of A. membranaceus is the medicinal tissue widely used due to their beneficial effects to lung health, which has been further proved to exhibit immunomodulatory, antioxidant, antiperspirant, antidiarrheal, and antidiabetic activities [2]. The bioactive compounds in the root of $A$. membranaceus are complicated. Previous research has revealed that the main bioactivities depend on the presence of non-volatile components, such as polysaccharides, saponins, and phenolics [3,4].

Flavonoids are a natural bioactive compound with C6-C3-C6 skeleton. They are commonly found in plant species, and possess good bioactivities which have been applied in nutraceutical, medicinal, and cosmetic products [5]. Many different subclasses of flavonoids have been described from A. membranaceus including flavone, flavonol, flavanone, flavanonol, chalcone, aurone, isoflavone, and pterocarpan [6]. Phenolics, including flavonoids, have been judged as the marker for quality evaluation and standardization of A. membranaceus and its processed products [7]. Methoxylated flavonoids and their glycosides, such as calycosin and calycosin-7-O- $\beta$-D-glucoside, were the major bioactive constituents of $A$. membranaceus due to their superior bioactivities [8,9]. After glycosylation and methylation, the reactivity and solubility of the flavonoids usually improved and thereby so did their absorption and bioactivity [10]. Many methoxyl flavones and flavonoid glycosides have been proved the superior antioxidant activities [11,12]. Due to the plant origin and extremely low toxicity, they have become the hotspots of natural antioxidants drug discovery and development $[13,14]$. 
The accumulation of bioactive compounds depends on geographical location and growing environment, including climate, soil, and fertilizer [15]. It is highly correlated to the health benefits and pharmaceutical activities. Different origins usually lead to different phytochemical profiles, which further relate to the quality of A. membranaceus. However, relevant information regarding this topic is limited. Therefore, in the present study, A. membranaceus from four production origins (Gansu, Shanxi, Inner Mongolia, and Heilongjiang provinces of China) were collected and the flavonoids were identified by ultra-high-performance liquid chromatography-tandem mass spectrometry (UHPLCMS/MS). Afterward, the antioxidant activities were investigated by ORAC assay, DPPH radical scavenging activity assay and CAA assay. These results help to understand the qualities of $A$. membranaceus from different origins.

\section{Materials and Methods}

\subsection{Plant Materials and Reagents}

The dried root of A. membranaceus samples were obtained from Shanxi, Inner Mongolia, Gansu, and Heilongjiang provinces, respectively. They were screened for the consistency of shape, diameter, and length. The reagents used in the present work were of analytical grade. The methanol was purchased from Macklin Biochemical Co., Ltd. (Shanghai, China). Folin-Ciocalteu reagent, sodium carbonate $\left(\mathrm{Na}_{2} \mathrm{CO}_{3}\right)$, aluminum chloride $\left(\mathrm{AlCl}_{3}\right)$, sodium nitrite $\left(\mathrm{NaNO}_{2}\right)$, sodium hydroxide $(\mathrm{NaOH})$, potassium dihydrogen phosphate $\left(\mathrm{KH}_{2} \mathrm{PO}_{4}\right)$, and dipotassium hydrogen phosphate $\left(\mathrm{K}_{2} \mathrm{HPO}_{4}\right)$ were obtained from Sangon Biotech (Shanghai, China). Gallic acid, catechin, ascorbic acid, fluorescein sodium, trolox, 1,1-diphenyl-2-picryldydrazyl (DPPH), 3-(4,5-dimethylthiazol-2-yl)-5(3carboxymethonyphenol)-2-(4-sulfophenyl)-2H-tetrazolium (MTS), glutamic acid, and 2,2' azobis-amidinopropane (ABAP) were purchased from Sigma Chemical Co. (St. Louis, MO, USA). HPLC-grade methanol was obtained from Merck Co., Ltd. (Darmstadt, Germany). Dulbecco's modified Eagle's medium (DMEM), fetal bovine serum (FBS), and phosphate-buffered saline (PBS) for cell culture were purchased from Gibco Life Technologies (Grand Island, NY, USA). All the other chemicals were obtained from Tianjin Chemical Reagent Co. (Tianjin, China).

\subsection{Extraction}

The bioactive compounds were extracted as explained previously by Wu et al. [16] with some modifications. Five hundred milligrams of A. membranaceus root powder were extracted with $5 \mathrm{~mL}$ of methanol for one week in dark at room temperature. The extract was centrifuged at $9000 \times g$ for $20 \mathrm{~min}$. Then the supernatants were collected and concentrated at $45^{\circ} \mathrm{C}$ by a vacuum rotary evaporator (Eyela N-1100 V-W, Tokyo Ri-kakikai Co. Ltd., Tokyo, Japan). The aliquots were stored at $4{ }^{\circ} \mathrm{C}$ before use. The extraction was conducted in triplicate.

\subsection{Determination of Total Phenolics and Flavonoids Contents}

The content of total phenolics was determined by using Folin-Ciocalteu colorimetric protocol [17]. Briefly, an aliquot $(1 \mathrm{~mL})$ of the extract or standard solution of gallic acid $(0,20,60,100,150,200,300,400,500$, and $600 \mu \mathrm{g} / \mathrm{mL})$ was mixed with $0.4 \mathrm{~mL}$ of distilled water and incubated for $6 \mathrm{~min}$ with $0.1 \mathrm{~mL}$ of Folin-Ciocalteu phenol reagent. Then $1.0 \mathrm{~mL}$ of $\mathrm{Na}_{2} \mathrm{CO}_{3}(7 \%, w / v)$ and $0.8 \mathrm{~mL}$ of distilled water were added to the mixture. After incubation for $90 \mathrm{~min}$ at room temperature, the absorbance was measured at $760 \mathrm{~nm}$ by using a multi-mode microplate reader (Spark, Tecan Group Ltd., Männedorf, Switzerland). The total phenolics contents were finally expressed as milligram of gallic acid equivalents per $100 \mathrm{~g}$ dry weight of $A$. membranaceus (mg GAE/100 g DW).

The total flavonoids content was measured by aluminium chloride colorimetric assay [18]. In brief, an aliquot $(1 \mathrm{~mL})$ of the extract or standard solutions of catechin $(0,20,60$, $100,150,200,300,400,500$, and $600 \mu \mathrm{g} / \mathrm{mL}$ ) was added with $400 \mu \mathrm{L}$ of $80 \%$ methanol and $50 \mu \mathrm{L}$ of $\mathrm{NaNO}_{2}(5 \%, w / v)$ before incubation for $6 \mathrm{~min}$. Afterward, $50 \mu \mathrm{L}$ of $\mathrm{AlCl}_{3}(10 \%, w / v)$ 
were added. After another $6 \mathrm{~min}, 400 \mu \mathrm{L}$ of $\mathrm{NaOH}(4 \%, w / v)$ were added to the mixture and further incubated for $15 \mathrm{~min}$. The absorbance was measured at $510 \mathrm{~nm}$. Catechin was chosen as the standard. The total flavonoids contents were expressed as milligrams of catechin equivalents per $100 \mathrm{~g}$ dry weight of $A$. membranaceus (mg CE/100 g DW).

\subsection{UHPLC and UHPLC-MS/MS Analyses}

UHPLC analysis was applied to isolate the bioactive compounds presented in A. membranaceus. A Thermo Scientific Ultimate 3000 UHPLC system coupled with an Orbitrap Elite (Thermo Fisher Scientific, Waltham, MA, USA) was used. A C18 column $(3.0 \times 100 \mathrm{~mm}$, $1.8 \mu \mathrm{m}$, Agilent, Santa Clara, CA, USA) was equipped. The samples were eluted with a gradient system consisting of solvent $\mathrm{A}(0.1 \%$ formic acid in water, $v / v)$ and solvent $\mathrm{B}(0.1 \%$ formic acid in acetonitrile, $v / v)$. A gradient elution program was conducted as follows: $0-3 \mathrm{~min}, 3 \%$ solvent $\mathrm{B}$; $3-24 \mathrm{~min}$, from $3 \%$ to $95 \%$ solvent $\mathrm{B} ; 24-29 \mathrm{~min}, 95 \%$ solvent $\mathrm{B} ; 29-30 \mathrm{~min}$, from $95 \%$ to $3 \%$ solvent $\mathrm{B} ; 30-35 \mathrm{~min}, 3 \%$ solvent $\mathrm{B}$. The flow rate was $0.4 \mathrm{ml} / \mathrm{min}$ and the injection volume was $2 \mu \mathrm{L}$. The column temperature was maintained at $35^{\circ} \mathrm{C}$. Electron spray ionization of the analytes was used in positive mode. Mass spectra were collected in the full-scan mode in a mass range of 100-1000 Da. The MS/MS spectra were obtained with collision energy of $25 \mathrm{eV}$.

\subsection{Determination of Oxygen Radical Absorbance Capacity (ORAC)}

The oxygen radical absorbance capacity assay was conducted by following the protocol of literature [19]. The fluorescein sodium salt and ABAP were dissolved in $75 \mathrm{mM}$ PBS buffer ( $\mathrm{pH}$ 7.4), respectively. A total $20 \mu \mathrm{L}$ of sample solution or positive control or blank were added in 96-well microplate (Corning Scientific, Corning, NY, USA) and incubated for $30 \mathrm{~min}$ at $37^{\circ} \mathrm{C}$. Then, $200 \mu \mathrm{L}$ of fluorescein sodium salt $(0.96 \mu \mathrm{M})$ were added. After incubating for $20 \mathrm{~min}, 20 \mu \mathrm{L}$ of ABAP $(119 \mathrm{mM})$ were added to the mixture and measured immediately at $37^{\circ} \mathrm{C}$. The fluorescence generation was monitored every $1.5 \mathrm{~min}$ for 60 cycles by using a multi-mode microplate reader (excitation wavelength of $480 \mathrm{~nm}$, and emission wavelength of $520 \mathrm{~nm}$ ). The Trolox equiv (TE) solutions $(6.25,12.5$, 25 , and $50 \mu \mathrm{M}$ ) were used as the positive control, and $75 \mathrm{mM}$ phosphate ( $\mathrm{pH} 7.4$ ) was used as the blank. ORAC values were expressed as $\mu \mathrm{mol}$ of Trolox equivalents per gram of A. membranaceus methyl extract ( $\mu \mathrm{mol} \mathrm{TE} / \mathrm{g}$ ) on the basis of the regression equation between Trolox concentration and the net area under the curve (AUC).

\subsection{Determination of DPPH Radical Scavenging Activity}

The DPPH radical scavenging activity of extract was evaluated by using the method described previously [20]. The DPPH in methanol $(100 \mu \mathrm{M})$ was prepared freshly, and ascorbic acid (AA) was prepared as the positive control. A total $180 \mu \mathrm{L}$ of DPPH in methanol were added into $20 \mu \mathrm{L}$ of sample solutions and incubated for $30 \mathrm{~min}$ in dark at room temperature. Afterward, the absorbance was measured at $517 \mathrm{~nm}$ immediately. The vehicle control was set up by using methanol instead of the sample. The DPPH scavenging activity was calculated according to the following equation: Scavenging activity (\%) = $(1-$ absorbance of sample/absorbance of control $) \times 100$, and the $\mathrm{IC}_{50}$ value was calculated on the scavenging activity against DPPH radicals and expressed as $\mu \mathrm{mol}$ of ascorbic acid per gram of A. membranaceus extract ( $\mu \mathrm{mol} \mathrm{AA} / \mathrm{g})$.

\subsection{Cytotoxicity Assay}

HepG2 cells were obtained from the laboratory of Animal Center, Sun Yat-Sen University, China. The cells were cultured in William's medium E (WME) supplemented with 5\% FBS (Gibco Life Technologies, Grand Island, NY, USA), 50 units/mL penicillin, $2 \mathrm{mM}$ glutamine, $100 \mu \mathrm{g} / \mathrm{mL}$ gentamicin, $10 \mathrm{mM}$ Hepes, $50 \mu \mathrm{g} / \mathrm{mL}$ streptomycin, $5 \mu \mathrm{g} / \mathrm{mL}$ insulin, and $0.05 \mu \mathrm{g} / \mathrm{mL}$ hydrocortisone. Then the cell was cultured in a humidified incubator at $37{ }^{\circ} \mathrm{C}$ with $5 \% \mathrm{CO}_{2}$. 
The cytotoxicity assay was performed by the MTS staining method. Briefly, HepG2 cells were seeded in a 96-well microplate with a concentration of $4 \times 10^{4}$ cells / well. After incubation for $24 \mathrm{~h}$, the cells were collected by removing the growth medium from each well and were washed by PBS buffer. The sample with various concentrations $(0,25,50$, $100,200 \mu \mathrm{g} / \mathrm{mL})$ was used to treat the cells for $24 \mathrm{~h}$. MTS solution $(50 \mu \mathrm{g} / \mathrm{mL})$ was added to each well and incubated for $4 \mathrm{~h}$. The absorbance was measured at $570 \mathrm{~nm}$.

\subsection{Cellular Antioxidant Activity}

The cellular antioxidant activity was analysed as previously reported [19]. Briefly, HepG2 cells were seeded at $6 \times 10^{4}$ cells/well in a black 96-well microplate and inoculated at $37^{\circ} \mathrm{C}$ for $24 \mathrm{~h}$. The growth medium was then removed and each well was washed with $100 \mu \mathrm{L}$ of PBS buffer. Afterward, the wells were treated with $100 \mu \mathrm{L}$ of WME medium containing different concentrations of samples $(0,3.125,6.25,12.5,25,50 \mu \mathrm{g} / \mathrm{mL})$ and $50 \mu \mathrm{M}$ 2,7-diacetate dichlorofluorescein (DCFH-DA) were added to the cells and incubated for $1 \mathrm{~h}$ (Trolox at 3.125, 6.25, 12.5, 25, and $50 \mathrm{mM}$ were used as control). The treatment solution was removed, and the 96-well microplate was washed three times with PBS, followed by the addition of an oxidant-supplemented medium (HBSS with 10 mM HEPES, $600 \mu \mathrm{M}$ ABAP). The 96-well microplates were transferred to a multimode microplate reader. The fluorescence was recorded every $5 \mathrm{~min}$ for $1 \mathrm{~h}$ at $37^{\circ} \mathrm{C}$ with an emission wavelength of $538 \mathrm{~nm}$ and excitation wavelength of $485 \mathrm{~nm}$. After subtraction of the blank from each sample measurement, the area under the curve for fluorescence versus time was integrated to calculate CAA value as follows: CAA (units) $=1-\left(\int \mathrm{SA} / \int \mathrm{CA}\right)$. In this equation, $\int \mathrm{SA}$ is the integrated area under the fluorescence-time curve of samples, and $\int \mathrm{SA}$ represents the integrated area under the curve of the control. By referring to the regression equation of concentration and $\mathrm{CAA}$ value, the $\mathrm{EC}_{50}$ values and quercetin equivalents were calculated.

\subsection{Statistical Analysis}

All the experiments were performed in triplicate and the results were expressed as mean \pm standard deviation. The peak heights of chemicals in mass spectra were recorded and averaged over three replicates. Principal component analysis (PCA) was performed to obtain an overview of variations between data. Meanwhile, a supervised multivariate statistical method, orthogonal partial least square discriminant analysis (OPLSDA) mode was built to find the analytes in the data with variable importance in the projection. Moreover, variable importance in projection (VIP) is an important index. The differential constituents were selected based on VIP values $>1$ and $p$-values from Student's $t$-test $<0.05$ [21]. Heatmap was applied to visualize the number of differential metabolites and to analyse their hierarchical cluster. The results were subjected to analysis of variance and differences between means by using ANOVA test followed by Tukey's test or Dunnett's test. In all the tests, the differences between results were regarded as significant at $p<0.05$.

\section{Results}

\subsection{Total Phenolics and Flavonoids}

The yield of A. membranaceus extract were $17.11 \%$ (Gansu), 16.84\% (Shanxi), 14.84\% (Heilongjiang), and $10.13 \%$ (Inner Mongolia), respectively. Total phenolics and flavonoids contents of $A$. membranaceus root from four origins are presented in Figure 1 . The content of phenolics varied between 135.23-197.40 mg GAE/g extract and in a decreasing order of 'Inner Mongolia' (197.40 \pm 1.95 mg GAE/g extract), 'Heilongjiang' (164.93 \pm 2.14 mg GAE/g extract), 'Shanxi' (155.62 $\pm 0.95 \mathrm{mg} \mathrm{GAE} / \mathrm{g}$ extract), and 'Gansu' (135.24 $\pm 1.66 \mathrm{mg}$ GAE/g extract), respectively. Among them, the 'Inner Mongolia' and 'Heilongjiang' samples presented significantly $(p<0.05)$ higher levels of phenolics than the other two origins. Meanwhile, the total flavonoids contents of $A$. membranaceus were significantly different among the four origins. It ranged from 52.27 to $112.75 \mathrm{mg} \mathrm{CE} / \mathrm{g}$ extract. Among them, the 'Inner Mongolia' samples (112.75 $\pm 0.77 \mathrm{mg} \mathrm{CE} / \mathrm{g}$ extract) presented significantly higher $(p<0.05)$ flavonoids contents than the other three origins, followed by 'Gansu' 
(67.22 $\pm 3.67 \mathrm{mg}$ CE/g extract) and 'Shanxi' (69.12 $\pm 6.59 \mathrm{mg}$ CE/g extract) samples. Unlike the trend of phenolic compounds, a relatively low flavonoids content was observed in 'Heilongjiang' sample (52.27 $\pm 4.63 \mathrm{mg} \mathrm{CE} / \mathrm{g}$ extract), which indicated the presence of non-flavonoids phenolics.

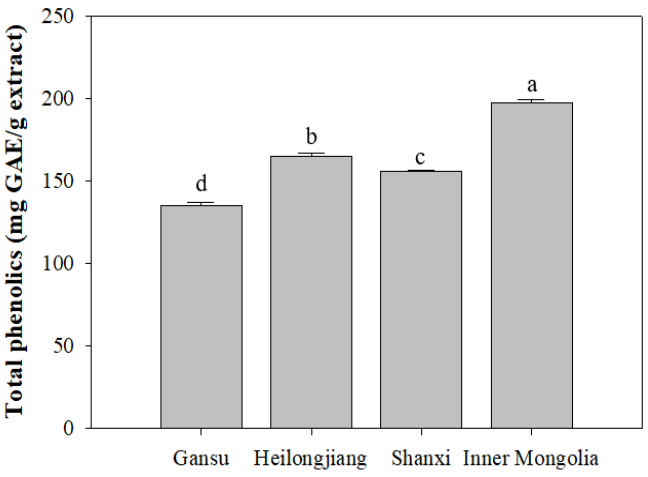

(A)

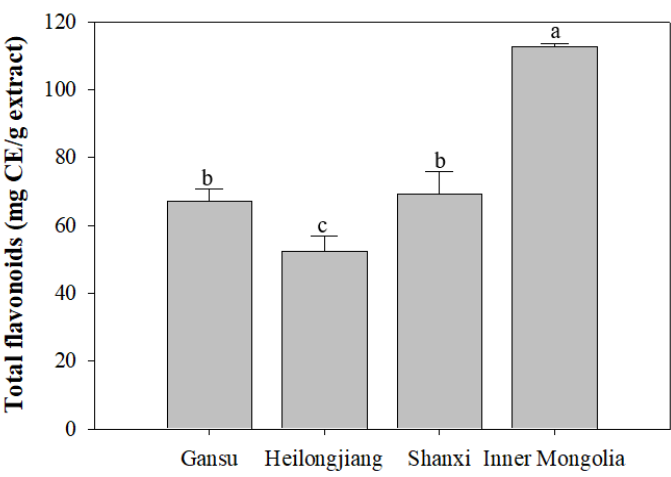

(B)

Figure 1. Total phenolics and total flavonoids contents of $A$. membranaceus roots from different origins (Gansu, Inner Mongolia, Shanxi, and Heilongjiang). (A), total phenolics contents; (B), total flavonoids contents. Values in one column with different letters are significantly different $(p<0.05)$.

It is widely known that a diet rich in fruit and vegetables has a protective effect against cancer insurgence and development. In the presence of an intense stressing event, cells activate specific responses to counteract cell death or senescence, which is known to act as a key task in the onset of age-related pathologies and the loss of tissue homeostasis [22]. Phenolics are generally recognized to be responsible for antioxidant and anti-aging effects, as well other beneficial actions [23]. Previous research showed that the total phenolic content of A. membranaceus from Western Siberia ranged from 100-190 mg GAE/g extract [24], which is consistent with this study. The total phenolics and flavonoids contents of $A$. membranaceus from Shijiazhuang origin were $27.646 \pm 0.11 \mathrm{mg}$ GAE $/ \mathrm{g}$ extract and $7.048 \pm 0.87 \mathrm{mg} R E / g$ extract, respectively [25]. The difference of total phenolics and flavonoids contents distinguished the $A$. membranaceus materials from different origins clearly.

\subsection{Identification of Bioactive Compounds}

The UHPLC-MS/MS analysis of the methanolic extract was performed to characterize the bioactive compounds of $A$. membranaceus. The total ion chromatogram was presented in positive ion mode. After preliminary comparative analysis by retention time, MS/MS fragments, and the reported data in references or Compound Discoverer, 34 flavonoids were identified, including 13 methoxylated flavonoids, 15 flavonoid glycosides, and 6 flavonols. The compounds identified by UHPLC-MS/MS spectra are summarized in Table 1, and their putative fragmentation pathways are shown in Figure 2. The identification of methoxylated flavonoids and flavonoids glycosides were explained in detail as follows.

\subsubsection{Polymethoxylated Flavonoids}

Polymethoxylated flavonoids are characteristic compounds distributed in Astragalus species. In positive ion mode, the main feature of the fragmentation of $[\mathrm{M}+\mathrm{H}]^{+}$ions of methoxylated flavonoids is the loss of methyl radical (form the fragment ions of $[\mathrm{M}+\mathrm{H}-$ $\left.\left.\mathrm{nCH}_{3}\right]^{+}\right)$. Besides, neutral loss could be observed, such as $28(\mathrm{CO})$ and $44\left(\mathrm{CO}_{2}\right)$. The $\mathrm{C}$ ring of flavonoids was less stable and prone to be cleaved resulting in various retroDiels Alder fragments [26]. The even-electron rule could be applied for the identification of methoxylated flavonoids [27]. For example, compound 29 with the retention time of $15.87 \mathrm{~min}$ was identified as formononetin due to the quasi-molecular ion peak at $\mathrm{m} / \mathrm{z}$ $269.077\left([\mathrm{M}+\mathrm{H}]^{+}\right)$. The characteristic MS/MS ion peak at $m / z 254.056\left(\left[\mathrm{M}+\mathrm{H}-\mathrm{CH}_{3}\right]^{+}\right)$ 
was detected. A dominant fragment ion ${ }^{1,3} \mathrm{~A}^{+}$at $m / z 137.022$ was presented due to the breakage of $C$ ring. Similarly, vesticarpan (22) at the retention time of $14.37 \mathrm{~min}$ had a quasi-molecular ion at $m / z 287.089\left([\mathrm{M}+\mathrm{H}]^{+}\right)$. The fragment at 273.068 matched the loss of a methyl residue $\left(\left[\mathrm{M}+\mathrm{H}-\mathrm{CH}_{3}\right]^{+}\right)$and yielded secondary fragment ions at $m / z 165.054$ $\left({ }^{6,7} \mathrm{~A}^{+}\right)$and $139.035\left({ }^{1,3} \mathrm{~A}^{+}\right)$. Furthermore, the fragment ion at $m / z 123.044$ was observed due to the loss of $18\left(\mathrm{H}_{2} \mathrm{O}\right)$. The putative fragmentation pathway is shown in Figure 2. Methylinissolin (20) at the retention time of $13.70 \mathrm{~min}$ had a base peak at $\mathrm{m} / z 315.201$ $\left([\mathrm{M}+\mathrm{H}]^{+}\right)$. The typical fragment at $m / z 300.062$ was detected due to the loss of methyl radical and yielded secondary fragment ions ${ }^{1,3} \mathrm{~A}^{+}$at $m / z$ 123.044. The A-ring and/or B-ring were easy to produce fragment ions due to the neutral loss of $\mathrm{CH}_{4}$. The peaks with the retention times of 13.10,13.14, 13.47, 13.66, 13.78, 14.81, 15.65, 15.66, and $16.09 \mathrm{~min}$ were assigned to be methoxylated flavonoids with $[\mathrm{M}+\mathrm{H}]^{+}$at $m / z 301.103,303.118,331.078$, $285.071,315.084,317.099,301.069,271.086$, and 299.088, respectively. These fragments were characterized by the losses of methyl radicals and fragment ${ }^{1,3} \mathrm{~A}^{+}$was the most abundant ion in all the spectra. These compounds were identified as 7-hydroxy-2'-methoxy- $4^{\prime}, 5^{\prime}$ methylenedioxyisoflavane (14), 2', 8-dihydroxy-4', $7^{\prime}$-dimethoxyisoflavane (16), chrysin (17), calycosin (19), odoratin (21), astragaluquinone (24), pratensein (26), pinostrobin (27), and

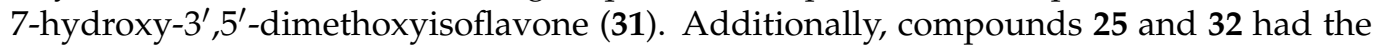
quasi-molecular ion peaks at $m / z 257.079$ and 273.183 were identified as isoliquiritigenin (25) and butein (32), two principle chalcones, which further formed secondary fragments at $m / z$ 149.061, 137.023, 121.065, and 165.091, 137.059, consistent with literature [28]. These were the characteristic fragment ions produced by chalcone fragmentation pathway (Figure 2A).

Table 1. The identified flavonoids compounds of Astragalus based on the UHPLC-ESI-MS/MS method.

\begin{tabular}{|c|c|c|c|c|c|}
\hline NO. & RT (Min) & Chemicals & {$[\mathrm{M}+\mathrm{H}]^{+}$} & Formula & MS2 Fragments $(m / z)$ \\
\hline 1 & 8.64 & Narcissin & 625.172 & $\mathrm{C}_{28} \mathrm{H}_{32} \mathrm{O}_{16}$ & 463.121 \\
\hline 2 & 9.41 & Nicotiflorin & 595.161 & $\mathrm{C}_{27} \mathrm{H}_{30} \mathrm{O}_{15}$ & $433.111,271.059$ \\
\hline 3 & 9.58 & Flagaloside D & 581.196 & $\mathrm{C}_{26} \mathrm{H}_{28} \mathrm{O}_{15}$ & $563.183,419.143$ \\
\hline 4 & 10.58 & Liquiritin & 419.129 & $\mathrm{C}_{21} \mathrm{H}_{22} \mathrm{O}_{9}$ & 257.071 \\
\hline 5 & 10.77 & Licoagroside D & 449.140 & $\mathrm{C}_{22} \mathrm{H}_{24} \mathrm{O}_{10}$ & 287.081 \\
\hline 6 & 10.88 & Calycosin 7-O-glucoside & 447.124 & $\mathrm{C}_{22} \mathrm{H}_{22} \mathrm{O}_{10}$ & $285.074,270.051$ \\
\hline 7 & 10.98 & Odoratin 7-O-glucoside & 477.135 & $\mathrm{C}_{23} \mathrm{H}_{24} \mathrm{O}_{11}$ & $315.085,300.062$ \\
\hline 8 & 11.21 & Apigenin 7-O-glucoside & 433.108 & $\mathrm{C}_{21} \mathrm{H}_{20} \mathrm{O}_{10}$ & $401.119,271.059$ \\
\hline 9 & 11.67 & Biochanin A 7-O-(6-O-malonyl-glucoside) & 533.124 & $\mathrm{C}_{25} \mathrm{H}_{24} \mathrm{O}_{13}$ & $489.137,447.126,285.075,270.052$ \\
\hline 10 & 11.78 & Pratensein $7-O$-glucoside & 463.119 & $\mathrm{C}_{22} \mathrm{H}_{22} \mathrm{O}_{11}$ & $301.069,286.050$ \\
\hline 11 & 12.54 & Ononin & 431.130 & $\mathrm{C}_{22} \mathrm{H}_{22} \mathrm{O}_{9}$ & $269.079,254.057$ \\
\hline 12 & 12.88 & Methylinissolin 3-O-glucoside & 463.155 & $\mathrm{C}_{23} \mathrm{H}_{26} \mathrm{O}_{10}$ & $445.149,301.105,165.054$ \\
\hline 13 & 13.06 & Isomucronulatol 7-O-glucoside & 465.171 & $\mathrm{C}_{23} \mathrm{H}_{28} \mathrm{O}_{10}$ & $447.164,303.122,275.090$ \\
\hline 14 & 13.10 & $\begin{array}{l}\text { 7-Hydroxy-2'-methoxy- } 4^{\prime}, 5^{\prime}- \\
\text { methylenedioxyisoflavane }\end{array}$ & 301.103 & $\mathrm{C}_{17} \mathrm{H}_{16} \mathrm{O}_{5}$ & $286.083,270.087,123.044$ \\
\hline 15 & 13.10 & Calycosin 7-O-\{6"-[-but-2-enoyl]\}-glucoside & 515.150 & $\mathrm{C}_{26} \mathrm{H}_{26} \mathrm{O}_{11}$ & $429.152,285.075,270.050$ \\
\hline 16 & 13.14 & $2^{\prime}, 8$-Dihydroxy-4', 7-dimethoxyisoflavane & 303.118 & $\mathrm{C}_{17} \mathrm{H}_{18} \mathrm{O}_{5}$ & $275.091,153.054,123.044$ \\
\hline 17 & 13.47 & Chrysin & 331.078 & $\mathrm{C}_{17} \mathrm{H}_{14} \mathrm{O}_{7}$ & $316.056,137.029$ \\
\hline 18 & 13.60 & Kaempferol & 287.090 & $\mathrm{C}_{15} \mathrm{H}_{10} \mathrm{O}_{6}$ & $271.054,153.054,137.023$ \\
\hline 19 & 13.66 & Calycosin & 285.071 & $\mathrm{C}_{16} \mathrm{H}_{12} \mathrm{O}_{5}$ & $270.051,137.023$ \\
\hline 20 & 13.70 & Methylinissolin & 315.201 & $\mathrm{C}_{18} \mathrm{H}_{18} \mathrm{O}_{5}$ & $300.062,165.054$ \\
\hline 21 & 13.78 & Odoratin & 315.084 & $\mathrm{C}_{17} \mathrm{H}_{14} \mathrm{O}_{6}$ & $287.089,137.059$ \\
\hline 22 & 14.37 & Vesticarpan & 287.089 & $\mathrm{C}_{16} \mathrm{H}_{14} \mathrm{O}_{5}$ & $272.068,165.054,123.044$ \\
\hline 23 & 14.52 & Apigenin & 271.059 & $\mathrm{C}_{15} \mathrm{H}_{10} \mathrm{O}_{5}$ & $153.017,137.019$ \\
\hline 24 & 14.81 & Astragaluquinone & 317.099 & $\mathrm{C}_{17} \mathrm{H}_{16} \mathrm{O}_{6}$ & $302.073,123.044$ \\
\hline 25 & 15.44 & Isoliquiritigenin & 257.079 & $\mathrm{C}_{15} \mathrm{H}_{12} \mathrm{O}_{4}$ & $149.061,137.023,121.065$ \\
\hline 26 & 15.65 & Pratensein & 301.069 & $\mathrm{C}_{16} \mathrm{H}_{12} \mathrm{O}_{6}$ & $286.046,153.018$ \\
\hline 27 & 15.66 & Pinostrobin & 271.086 & $\mathrm{C}_{16} \mathrm{H}_{14} \mathrm{O}_{4}$ & $256.062,137.059$ \\
\hline 28 & 15.84 & Daidzein & 255.099 & $\mathrm{C}_{15} \mathrm{H}_{10} \mathrm{O}_{4}$ & $137.059,119.044$ \\
\hline 29 & 15.87 & Formonentin & 269.077 & $\mathrm{C}_{16} \mathrm{H}_{12} \mathrm{O}_{4}$ & $254.056,137.022$ \\
\hline 30 & 16.06 & Garbanzol & 273.183 & $\mathrm{C}_{15} \mathrm{H}_{12} \mathrm{O}_{5}$ & $255.173,137.059$ \\
\hline 31 & 16.09 & 7-Hydroxy-3', $5^{\prime}$-dimethoxyisoflavone & 299.088 & $\mathrm{C}_{17} \mathrm{H}_{14} \mathrm{O}_{5}$ & $284.067,271.058,137.058$ \\
\hline 32 & 16.65 & Butein & 273.183 & $\mathrm{C}_{15} \mathrm{H}_{12} \mathrm{O}_{5}$ & $165.091,137.059$ \\
\hline 33 & 17.81 & $3^{\prime}, 6$-Dihydroxy-4'-methoxy-aurone & 285.073 & $\mathrm{C}_{16} \mathrm{H}_{12} \mathrm{O}_{5}$ & $285.075,270.051,121.027$ \\
\hline 34 & 18.49 & Astragaisoflavane D & 603.218 & $\mathrm{C}_{34} \mathrm{H}_{34} \mathrm{O}_{10}$ & $287.091,272.068$ \\
\hline
\end{tabular}


<smiles>C[I-][C](C)C</smiles>

$[\mathrm{M}+\mathrm{H}]^{+} \mathrm{m} / \mathrm{z} 257.079$

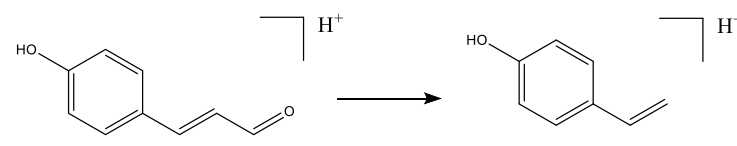

$[\mathrm{M}+\mathrm{H}]^{+} \mathrm{m} / \mathrm{z} 149.061$

$[\mathrm{M}+\mathrm{H}]^{+} \mathrm{m} / \mathrm{z} 121.065$<smiles>CC[IH+]CC</smiles>

$[\mathrm{M}+\mathrm{H}]^{+} \mathrm{m} / \mathrm{z} 137.023$

(A)

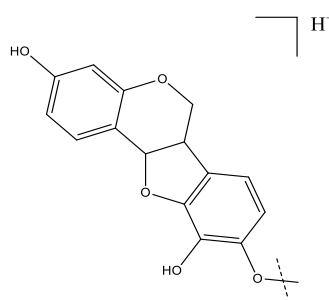

$[\mathrm{M}+\mathrm{H}]^{+} \mathrm{m} / \mathrm{z} 287.089$

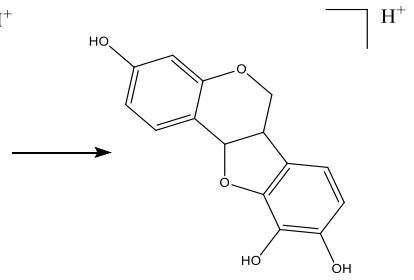

$[\mathrm{M}+\mathrm{H}]^{+} \mathrm{m} / \mathrm{z} 273.068$

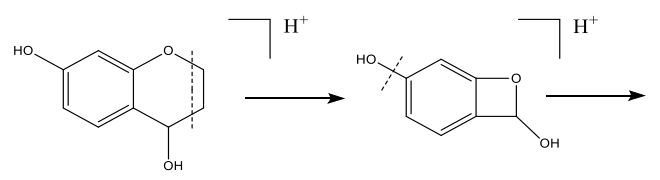

$[\mathrm{M}+\mathrm{H}]^{+} \mathrm{m} / \mathrm{z} 165.054$

$[\mathrm{M}+\mathrm{H}]^{+} \mathrm{m} / \mathrm{z} 139.035$

(B)

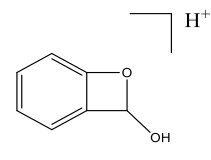

$[\mathrm{M}+\mathrm{H}]^{+} \mathrm{m} / \mathrm{z} 123.044$

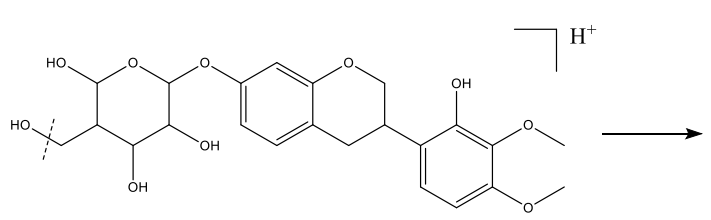

$[\mathrm{M}+\mathrm{H}]^{+} \mathrm{m} / \mathrm{z} 465.171$

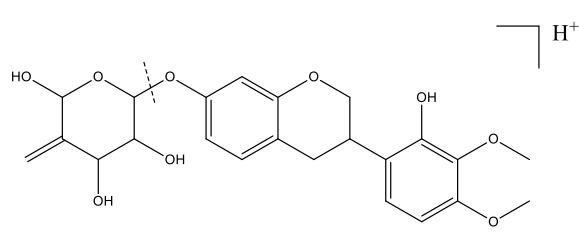

$[\mathrm{M}+\mathrm{H}]^{+} \mathrm{m} / \mathrm{z} 447.164$<smiles>COc1ccc(C2=COc3cc(O)ccc3C2)c(O)c1OC</smiles>

$[\mathrm{M}+\mathrm{H}]^{+} \mathrm{m} / \mathrm{z} 303.122$

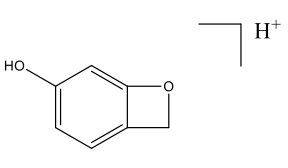

$[\mathrm{M}+\mathrm{H}]^{+} \mathrm{m} / \mathrm{z} 123.039$

(C)

Figure 2. The putative fragmentation pathways of isoliquiritigenin (A), vesticarpan (B), and isomucronulatol 7-O-glucoside (C).

\subsubsection{Flavonoid Glycosides}

Flavonoid glycosides, including flavonoid $C$-glycosides and $O$-glycosides, were two common patterns distributed in plants with multiple bioactivities [29]. In this study, 15 flavonoid O-glycosides were found in A. membranaceus, while 12 of them were identified to bound one or two methyls. After comparing the quasi-molecular ions and fragment ions in MS/MS spectra with those of previously reported literature [30,31], they were identified as narcissin (1), flagaloside D (3), licoagroside D (5), calycosin 7-O-glucopyranoside (6), odoratin 7-O-glucopyranoside (7), biochanin A 7-O-(6-O-malonyl-glucoside) (9), pratensein 7-O-glucopyranoside (10), ononin (11), methylinissolin 3-O-glucoside (12), isomucronulatol 7-O-glucoside (13), respectively. As reported previously, the application of low or medium 
fragmentation energy results in heterolytic cleavage of their hemiacetal $\mathrm{C}-\mathrm{O}$ bonds [32]. Besides, the losses of $18\left(\mathrm{H}_{2} \mathrm{O}\right), 28(\mathrm{CO}), 42\left(\mathrm{C}_{2} \mathrm{H}_{2} \mathrm{O}\right), 44\left(\mathrm{CO}_{2}\right)$ are also characteristic for flavonoid glycoside [33]. In the present work, flavonoid $\mathrm{O}$-glycosides showed similar fragmentation pattern. For instance, compound 13 with the retention time of 13.06 min was identified as isomucronulatol 7-O-glucoside due to the quasi-molecular ion peak at $m / z$ $465.17\left([\mathrm{M}+\mathrm{H}]^{+}\right)$and the characteristic MS /MS ion at $m / z 447.16\left(\left[\mathrm{M}+\mathrm{H}_{-}-\mathrm{H}_{2} \mathrm{O}\right]^{+}\right)$, and ion at $m / z 303.12\left(\left[\mathrm{M}_{-} \mathrm{C}_{6} \mathrm{H}_{10} \mathrm{O}_{5}\right]^{+}\right)$corresponding to the loss of a glucose moiety. The possible fragmentation pattern is proposed in Figure 2C. Furthermore, Compound 11, with parent ion at $m / z 412.54$, was identified as ononin $\left(\mathrm{C}_{22} \mathrm{H}_{22} \mathrm{O}_{9}\right)$, which fragmented into daughter ion at $\mathrm{m} / z 269.08$ due to the loss of a glucose moiety and further yielded the ion at $\mathrm{m} / \mathrm{z}$ $254.06\left(\left[\mathrm{M}-\mathrm{C}_{6} \mathrm{H}_{10} \mathrm{O}_{5}-\mathrm{CH}_{3}\right]^{+}\right)$, consistent with the reported data [34]. Compound 6, with the base peak at $m / z 447.124\left([\mathrm{M}+\mathrm{H}]^{+}\right)$, matched the ion $\left[\mathrm{Y}_{0}\right]^{+}$at $m / z 285.074$ with the loss of a glucose residue. The presence of fragment at $\mathrm{m} / \mathrm{z} 270.051$ was due to the loss of a methyl radical $\left[\mathrm{Y}_{0}-\mathrm{CH}_{3}\right]^{+}$. Besides, methylinissolin 3-O-glucoside (12) at the retention time of $12.88 \mathrm{~min}$ had a quasi-molecular ion at $m / z 463.155\left([\mathrm{M}+\mathrm{H}]^{+}\right)$. The fragments at $m / z 445.149$ and 301.105 were attributed to $\left[\mathrm{M}+\mathrm{H}-\mathrm{H}_{2} \mathrm{O}\right]^{+}$and $\left[\mathrm{Y}_{0}+\mathrm{H}\right]^{+}$, respectively. The ion ${ }^{6,7} \mathrm{~A}^{+}$at $m / z 165.054$ was the dominant fragment ion due to the breakage of $\mathrm{C}$ ring. Moreover, the compounds 2, 4, and 8 with the retention times at 9.41, 10.58, and $11.21 \mathrm{~min}$ were identified as nicotiflorin, liquiritin, and apigenin 7-O-glucopyranoside with the same fragmentation pattern.

\subsubsection{Multivariate Statistical Analysis}

PCA analysis is an unsupervised method usually employed to determine patterns between multivariate samples. The PCA analysis showed a clear tendency of separation among A. membranaceus samples from four origins. Specifically, the first two principal components explained $77.9 \%$ of the total variance, in which the first principal component explained $51.2 \%$ and the second principal component explained $26.7 \%$. The first principal component was represented by the compounds such as nicotiflorin, liquiritin, ononin, 7-hydroxy-2'-methoxy-4' ' $^{\prime}$-methylenedioxyisoflavane, calycosin 7-O-\{6'--[-but-2-enoyl]\}glucoside, methylinissolin, isoliquiritigenin, daidzein, and astragaisoflavane D. Most of them presented higher content in the 'Inner Mongolia' extract. The supervised discriminant OPLS-DA was performed to classify the samples from four regions and find out the differential compounds. A model with $\mathrm{R}^{2} \mathrm{X}$ of $0.997, \mathrm{R}^{2} \mathrm{Y}$ of 0.998 , and $\mathrm{Q}^{2}$ of 0.99 was constructed. $R^{2} Y>0.9$ indicated an excellent fitted model, and Q2 $>0.9$ suggested a good repeatability and predictability of the model. As shown in Figure 3A, no serious outlier was observed. The outlier is the plot out of the ellipse, which is defined as the Hotelling's T2 range $95 \%$ confidence [35]. The samples from different origins exhibited good separation. The 'Heilongiiang' sample and 'Inner Mongolia' sample were separated significantly in $\mathrm{t}$ [1] direction. 'Gansu' sample and 'Shanxi' sample located near the centre of the model plane and stayed close to each other, which indicated that their chemical compositions were similar. According to the searching rule of VIP value $>1$ and $p$-value $<0.05$, a total of 18 phenolics were regarded as principal metabolites marked in red in Figure 3B. Six methoxylated flavonoids (compounds 7-hydroxy-2'-methoxy- $4^{\prime}, 5^{\prime}$-methylenedioxyisoflavane, $2^{\prime}$, 8-Dihydroxy-4' ${ }^{\prime}, 7$-dimethoxyisoflavane, calycosin, vesticarpan, pratensein, $3^{\prime}, 6$-dihydroxy$4^{\prime}$-methoxy-aurone), eight flavonoid glycosides (compounds flagaloside D, licoagroside D, calycosin 7-O-glucoside, biochanin A 7-O-(6-O-malonyl-glucoside), methylinissolin 3-Oglucoside, calycosin 7-O-\{6"-[-but-2-enoyl]\}-glucoside, nicotiflorin, apigenin 7-O-glucoside, while the first six of them having one or two methyl groups), and four flavonols (apigenin, isoliquiritigenin, daidzein, butein) were included. Different geographical locations led to the variation of metabolites accumulation. 


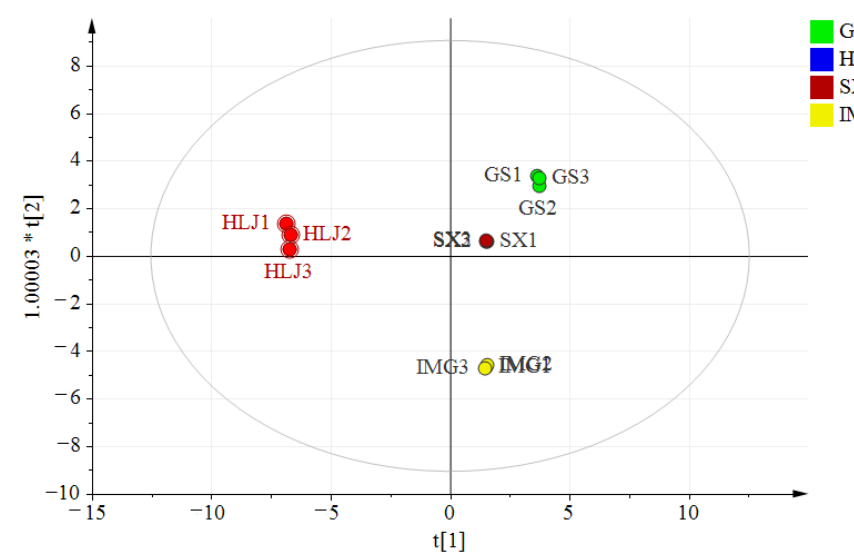

(A)

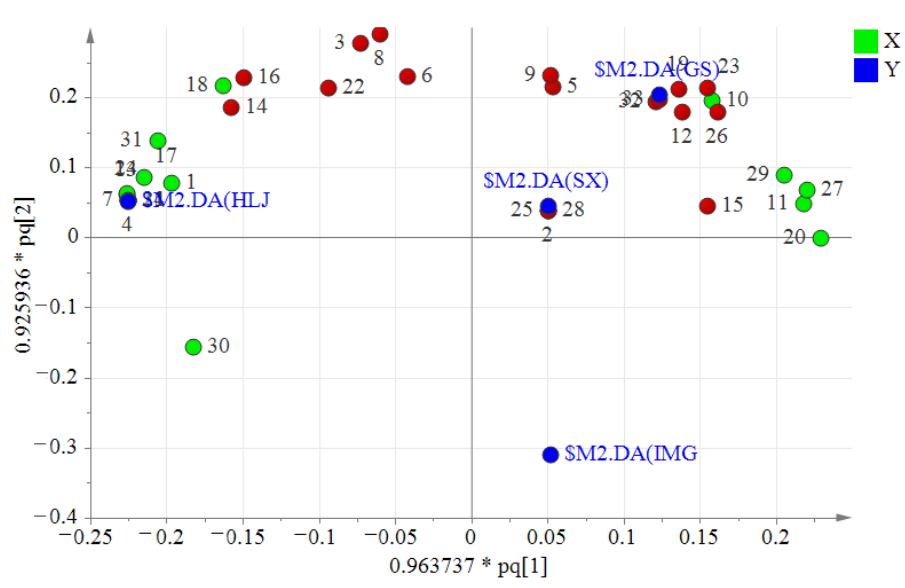

(B)

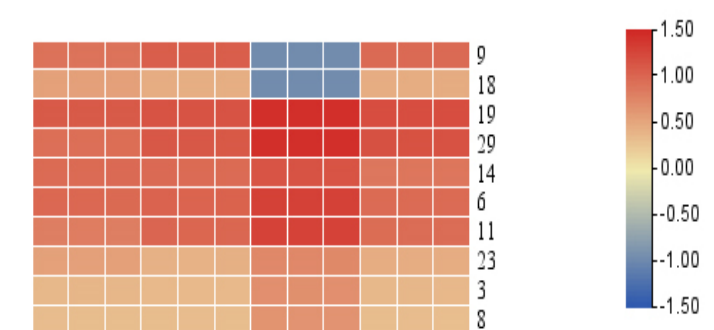

(C)

Figure 3. Multivariate statistical analysis of flavonoids in A. membranaceus from Gansu (GS), Heilongjiang (HLJ), Shanxi (SX), and Inner Mongolia (IMG): (A) OPLS-DA score plot; (B) OPLS-DA loading plot. The important compounds are in red colour. (C) Heatmap of phenolic components in astragalus from different origins. The levels of identified compounds were compared by their peak integration.

The heat map was applied to demonstrate the variation of the identified compounds. As shown in Figure 3C, 'Inner Mongolia' extract was rich in flavonoid glycosides and methoxylated flavonoids. Most principal flavonoids including flagaloside D, licoagroside $\mathrm{D}$, calycosin 7-O-glucoside, calycosin 7-O-\{6"1'-[-but-2-enoyl]\}-glucoside, apigenin 7-O-glucoside, 7-hydroxy-2'-methoxy-4' $4^{\prime}, 5^{\prime}$-methylenedioxyisoflavane, $2^{\prime}, 8$-dihydroxy-4', 7 dimethoxyisoflavane, calycosin, and pratensein all presented high levels in 'Inner Mongolia' samples than others. Besides, the principal methoxylated flavonoids such as vesticarpan and 6,3'-dihydroxy-4'-methoxy-auron were higher in the extract of 'Gansu' and 'Heilongjiang' samples than 'Shanxi' samples. Conversely, two principal flavonols (isoliquiritigenin and daidzein), only existed in 'Shanxi' sample. It could be used to distinguish 'Gansu' and 'Shanxi' samples. To compare the chemicals of 'Heilongiiang' with the other origins, the flavonoid glycosides and methoxylated flavonoids, such as flagaloside D, calycosin 7-O-glucopyranoside, apigenin 7-O-glucopyranoside, 7-hydroxy-2'-methoxy-4' $4^{\prime} 5^{\prime}$ methylenedioxyisoflavane, and 8, $2^{\prime}$-dihydroxy-7, $4^{\prime}$-dimethoxyisoflavane, were presented at relatively lower contents, which were defined as the characteristic compounds of the 'Heilongjiang' sample. 


\subsection{Antioxidant Activity}

\subsubsection{ORAC Value and DPPH Radical Scavenging Activity}

ORAC assay is a valid method to evaluate the antioxidant ability through monitoring the inhibition capacity against peroxyl radical [36]. The breakdown of ABAP can provide peroxyl radical and leads to subsequent oxidation. It can be monitored through fluorescent intensity change. As shown in Figure 4A, 'Inner Mongolia' (628.94 $\pm 3.30 \mu \mathrm{mol}$ TE/g extract) showed significant $(p<0.05)$ higher ORAC values. The ORAC values of other three samples were in a decreasing order of 'Gansu' (553.18 $\pm 15.28 \mu \mathrm{mol} \mathrm{TE} / \mathrm{g}$ extract), 'Shanxi' (522.48 $\pm 21.91 \mu \mathrm{mol} \mathrm{TE} / \mathrm{g}$ extract), and 'Heilongjiang' (471.29 $\pm 8.61 \mu \mathrm{mol} \mathrm{TE} / \mathrm{g}$ extract). It indicated that 'Inner Mongolia' and 'Gansu' extracts processed good peroxyl radical inhibition activities.

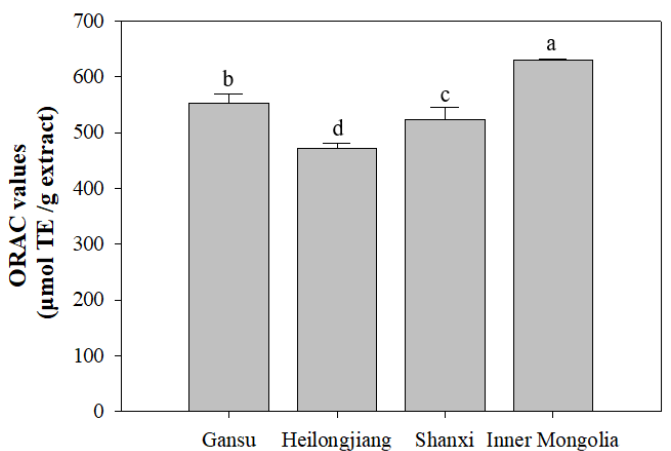

(A)

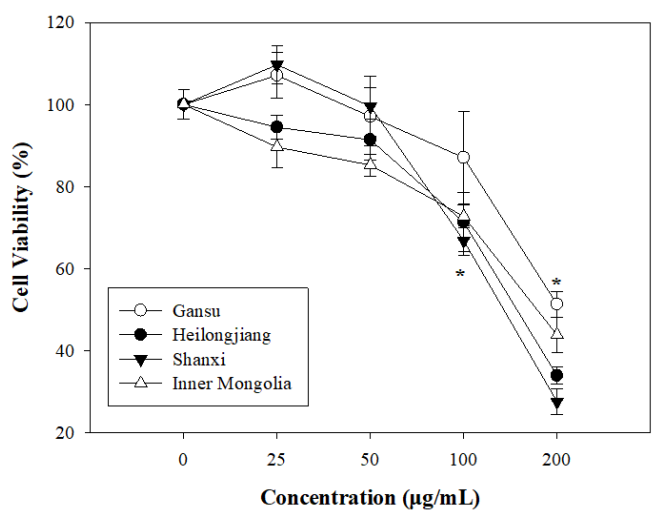

(C)

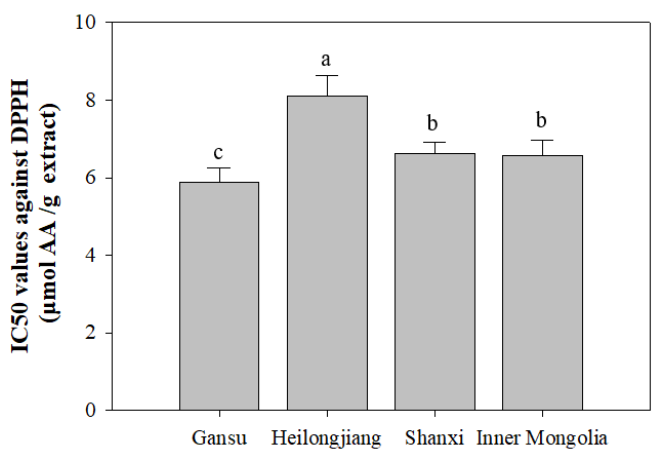

(B)

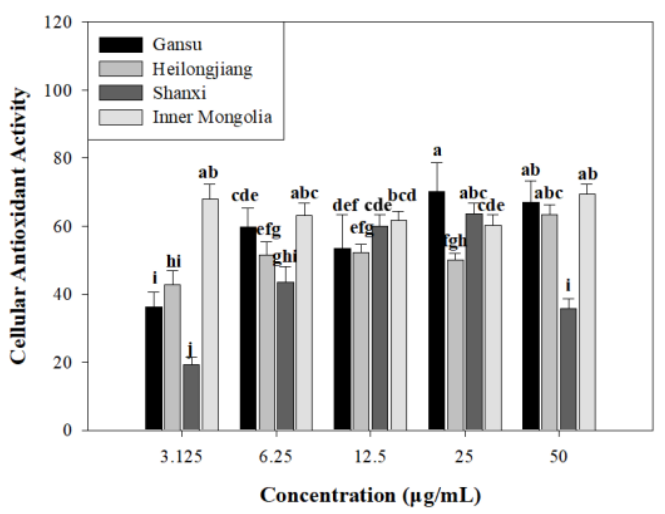

(D)

Figure 4. Antioxidant activities of Astragalus extracts from different origins. (A), ORAC value; (B), DPPH radical scavenging activity; (C), Cytotoxicity; (D), Cellular antioxidant activity. Different letters indicate values have significant differences $(p<0.05)$.

DPPH test is widely used to evaluate the antioxidant capacity of phenolics [37]. It is based on a stable nitrogen-centred free radical that is characterized by absorbance at $517 \mathrm{~nm}$ with a deep violet colour. In the presence of free radical scavenger, the absorbance of DPPH will decrease due to hydrogen donation from antioxidant with a dose-dependent behaviour [38]. As shown in Figure 4B, 'Heilongiiang' extract presented a higher DPPH radical scavenging activity with an $\mathrm{IC}_{50}$ value of $8.10 \pm 0.54 \mu \mathrm{mol} \mathrm{AA} / \mathrm{g}$ extract, followed by 'Shanxi' extract ( $\mathrm{IC}_{50}$ of $6.63 \pm 0.30 \mu \mathrm{mol} \mathrm{AA} / \mathrm{g}$ extract) and 'Inner Mongolia' extract ( $\mathrm{IC}_{50}$ of $6.57 \pm 0.40 \mu \mathrm{mol} \mathrm{AA} / \mathrm{g}$ extract). The 'Gansu' extract possessed the lowest $\mathrm{IC}_{50}$ value of $5.89 \pm 0.36 \mu \mathrm{mol}$ AA/g extract. This order was inconsistent with that of ORAC assay.

The occurrence of oxidation process is correlated with the existence of a surplus of free radicals, which are responsible for multiple diseases [39]. Peroxyl radicals are characterized as free radicals that predominate in the lipid oxidation of biological system [40]. Its inhibition plays an important role in disease prevention. Generally, the 
radical-trapping antioxidant activity of flavonoids is related to the hydrogen atom transfer to a peroxyl radical [41]. It can be used to explain the different radical-inhibitory activities of four origins samples. A. membranaceus from Lebanon possesses the lowest IC50 value of $102 \pm 4.4 \mu \mathrm{g} / \mathrm{mL}$ [42]. Several bioactive compounds have been confirmed. For example, formononetin, calycosin, and calycosin-7-O-glucoside showed superior antioxidant activity and inhibited free radicals generated by DPPH in a dose-dependent manner [43]. Moreover, calycosin can enhance antioxidant enzymatic activities such as glutathione peroxidase, catalase, superoxide dismutase and attenuate $\mathrm{H}_{2} \mathrm{O}_{2}$-induced $\mathrm{H}_{9} \mathrm{C}_{2}$ cell apoptosis rate in a dose-dependent manner as well [44]. Besides, the chemicals of formononetin from A. membranaceus have evidenced the capacity of inhibiting xanthine oxidase-induced cell injury significantly [45]. They were the major flavonoids in A. membranaceus.

\subsubsection{Cellular Antioxidant Activity (CAA)}

HepG2 cells line is a sensitive cell model in the determination of antioxidant biomarkers [46]. In the present work, the cytotoxic effects of $A$. membranaceus extract at different levels $(25,50,100$, and $200 \mu \mathrm{g} / \mathrm{mL}$ ) against HepG2 cells were determined by MTS assay. From the results summarized in Figure 4C, no significant cytotoxicities were observed between extract-treated cells and untreated cells within concentration of $0-50 \mu \mathrm{g} / \mathrm{mL}$. It indicated that this range could be used for cellular antioxidant activity assay.

The cellular antioxidant activities of $A$. membranaceus extracts were evaluated by CAA assay, and the results are shown in Figure 4D. It was obvious that the A. membranaceus extracts from four origins could protect HepG2 cells against peroxyl radicals with a dosedependent effect. Among them, 'Inner Mongolia' sample showed a higher CAA value than the others at $3.125 \mu \mathrm{g} / \mathrm{mL}$, while 'Gansu' and 'Shanxi' extracts exhibited higher CAA values at $25 \mu \mathrm{g} / \mathrm{mL}$. Trolox was used as positive control.

CAA assay is performed based on polarity, solubility, and molecular weight of the antioxidant and provides an important tool for the biological assessment of antioxidant activity [47]. In the CAA assay, the DCFH-DA is preloaded into the cell, treated with the intracellular peroxyl radicals generated from $\mathrm{ABAP}$ and therefore the fluorescence level is recorded [48]. Nuclear transcription factor, erythroid 2-like 2 (Nrf2) is a central conditioner of antioxidant response elements [49]. Phenolic compounds can protect $\mathrm{HepG}_{2}$ cell against oxidative injury by promoting the Nrf2 translocation, which subsequently attenuates oxidative DNA damage, induce the expression of antioxidant enzymes, and reduce cellular ROS formulation [50-52]. The antioxidant activities of phenolics usually depend on the chemical construction of attached functional groups and their permutation. Previous research has mentioned that methoxyl and hydroxyl groups are directly related to the radical-inhibited ability [53]. When the same skeleton was presented, the presence of methoxyl usually brings an enhanced antioxidant activity for phenolics. However, sometimes this substitution by methoxyl can diminish the antioxidant activity [54]. The substitution pattern on the B-ring is important to the antioxidant activity of flavonoids.

\section{Conclusions}

As mentioned above, thirty-four flavonoids in A. membranaceus from different origins were identified by UHPLC-MS/MS. Eighteen identified compounds were considered to be significantly important based on OPLS-DA analysis. It characterized the samples from different origins, especially for 'Heilongjiang' and 'Inner Mongolia'. Through antioxidant activity evaluation, 'Inner Mongolia' extract presented significantly higher ORAC and CAA values $(p<0.05)$. It was consistent with its higher phenolics and flavonoids contents. Further investigation on in vivo antioxidant mechanisms of those flavonoids is worthy to be conducted in the future.

Author Contributions: Conceptualization, supervision, funding acquisition, formal analysis, and writing-review editing, B.Y.; Formal analysis, and writing-review editing, J.L. and Y.J.; formal analysis, investigation, writing-original draft preparation, Z.S. All authors have read and agreed to the published version of the manuscript. 
Funding: This research was funded by National Natural Science Foundation of China (32071809).

Institutional Review Board Statement: Not applicable.

Informed Consent Statement: Not applicable.

Data Availability Statement: All data presented are available in the manuscript.

Conflicts of Interest: The authors declare that they have no competing interests.

\section{References}

1. Li, Y.; Guo, S.; Zhu, Y.; Yan, H.; Qian, D.W.; Wang, H.Q.; Yu, J.Q.; Duan, J.A. Comparative analysis of twenty-five compounds in different parts of Astragalus membranaceus var. mongholicus and Astragalus membranaceus by UPLC-MS/MS. J. Pharm. Anal. 2019, 9, 392-399. [CrossRef]

2. Fu, J.; Wang, Z.; Huang, L.; Zheng, S.; Wang, D.; Chen, S.; Zhang, H.; Yang, S. Review of the botanical characteristics, phytochemistry, and pharmacology of Astragalus membranaceus (Huangqi). Phytother. Res. 2014, 28, 1275-1283. [CrossRef] [PubMed]

3. Cho, W.C.S.; Leung, K.N. In vitro and in vivo immunomodulating and immunorestorative effects of Astragalus membranaceus. J. Ethnopharmacol. 2007, 113, 132-141. [CrossRef] [PubMed]

4. Sheng, Z.; Liu, J.; Yang, B. Structure differences of water soluble polysaccharides in Astragalus membranaceus induced by origin and their bioactivity. Foods 2021, 10, 1755. [CrossRef] [PubMed]

5. Dias, M.C.; Pinto, D.C.; Silva, A. Plant Flavonoids: Chemical Characteristics and Biological Activity. Molecules 2021, $26,5377$. [CrossRef] [PubMed]

6. Gong, G.; Zheng, Y.; Yang, Y.; Sui, Y.; Wen, Z. Pharmaceutical Values of Calycosin: One Type of Flavonoid Isolated from Astragalus. Evidence 2021, 2021, 9952578. [CrossRef]

7. Lin, L.Z.; He, X.G.; Lindenmaier, M.; Nolan, G.; Yang, J.; Cleary, M.; Qiu, S.X.; Cordell, G.A. Liquid chromatography-electrospray ionization mass spectrometry study of the flavonoids of the roots of Astragalus mongholicus and A. membranaceus. J. Chromatogr. A 2000, 876, 87-95. [CrossRef]

8. Wu, X.; Li, X.; Wang, W.; Shan, Y.; Wang, C.; Zhu, M.; La, Q.; Zhong, Y.; Xu, Y.; Nan, P. Integrated metabolomics and transcriptomics study of traditional herb Astragalus membranaceus Bge. var. mongolicus (Bge.) Hsiao reveals global metabolic profile and novel phytochemical ingredients. BMC Genom. 2020, 21, 1-16. [CrossRef]

9. Durazzo, A.; Nazhand, A.; Lucarini, M.; Silva, A.M.; Souto, S.B.; Guerra, F.; Severino, P.; Zaccardelli, M.; Souto, E.B.; Santini, A. Astragalus (Astragalus membranaceus Bunge): Botanical, geographical, and historical aspects to pharmaceutical components and beneficial role. Rend. Lincei. Sci. Fis. 2021, 32, 625-642. [CrossRef]

10. Johnson, J.B.; Mani, J.S.; Broszczak, D.; Prasad, S.S.; Ekanayake, C.P.; Strappe, P.; Valeris, P.; Naiker, M. Hitting the sweet spot: A systematic review of the bioactivity and health benefits of phenolic glycosides from medicinally used plants. Phytother. Res. 2021, 35, 1-25. [CrossRef]

11. Xiao, J. Dietary flavonoid aglycones and their glycosides: Which show better biological significance? Crit. Rev. Food Sci. Nutr. 2017, 57, 1874-1905. [CrossRef] [PubMed]

12. Li, S.; Tian, Y.; Jiang, P.; Lin, Y.; Liu, X.; Yang, H. Recent advances in the application of metabolomics for food safety control and food quality analyses. Crit. Rev. Food Sci. Nutr. 2021, 61, 1448-1469. [CrossRef] [PubMed]

13. Wang, J.F.; Liu, S.S.; Song, Z.Q.; Xu, T.C.; Liu, C.S.; Hou, Y.G.; Huang, R.; Wu, S.H. Naturally occurring flavonoids and isoflavonoids and their microbial transformation: A review. Molecules 2020, 25, 5112. [CrossRef]

14. Chen, L.; Wu, J.e.; Li, Z.; Liu, Q.; Zhao, X.; Yang, H. Metabolomic analysis of energy regulated germination and sprouting of organic mung bean (Vigna radiata) using NMR spectroscopy. Food Chem. 2019, 286, 87-97. [CrossRef] [PubMed]

15. Gai, Q.Y.; Jiao, J.; Wang, X.; Liu, J.; Wang, Z.Y.; Fu, Y.J. Chitosan promoting formononetin and calycosin accumulation in Astragalus membranaceus hairy root cultures via mitogen-activated protein kinase signaling cascades. Sci. Rep. 2019, 9, 10367. [CrossRef]

16. Dan, W.; He, J.; Jiang, Y.; Yang, B. Quality analysis of Polygala tenuifolia root by ultrahigh performance liquid chromatographytandem mass spectrometry and gas chromatography-mass spectrometry. J. Food Drug Anal. 2015, 1, $144-151$.

17. Vongsak, B.; Sithisarn, P.; Mangmool, S.; Thongpraditchote, S.; Wongkrajang, Y.; Gritsanapan, W. Maximizing total phenolics, total flavonoids contents and antioxidant activity of Moringa oleifera leaf extract by the appropriate extraction method. Ind. Crops Prod. 2013, 44, 566-571. [CrossRef]

18. John, B.; Sulaiman, C.; George, S.; Reddy, V. Total phenolics and flavonoids in selected medicinal plants from Kerala. Int. J. Pharm. Pharm. Sci. 2014, 6, 406-408.

19. Tu, J.; Shi, D.; Wen, L.; Jiang, Y.; Zhao, Y.; Yang, J.; Liu, H.; Liu, G.; Yang, B. Identification of moracin N in mulberry leaf and evaluation of antioxidant activity. Food Chem. Toxicol. 2019, 132, 110730. [CrossRef]

20. Liu, D.; Guo, Y.; Wu, P.; Wang, Y.; Golly, M.K.; Ma, H. The necessity of walnut proteolysis based on evaluation after in vitro simulated digestion: ACE inhibition and DPPH radical-scavenging activities. Food Chem. 2020, 311, 125960. [CrossRef]

21. Zhao, G.; Zhao, W.; Han, L.; Ding, J.; Chang, Y. Metabolomics analysis of sea cucumber (Apostichopus japonicus) in different geographical origins using UPLC-Q-TOF/MS. Food Chem. 2020, 333, 127453. [CrossRef] 
22. Arrigoni, R.; Ballini, A.; Santacroce, L.; Cantore, S.; Inchingolo, A.; Inchingolo, F.; Di Domenico, M.; Quagliuolo, L.; Boccellino, M. Another look at dietary polyphenols: Challenges in cancer prevention and treatment. Curr. Med. Chem. 2021, $28,42-53$. [CrossRef]

23. Di Domenico, M.; Feola, A.; Ambrosio, P.; Pinto, F.; Galasso, G.; Zarrelli, A.; Di Fabio, G.; Porcelli, M.; Scacco, S.; Inchingolo, F. Antioxidant Effect of Beer Polyphenols and Their Bioavailability in Dental-Derived Stem Cells (D-dSCs) and Human Intestinal Epithelial Lines (Caco-2) Cells. Stem Cells Int. 2020, 2020, 1-13. [CrossRef] [PubMed]

24. Babich, O.; Prosekov, A.; Zaushintsena, A.; Sukhikh, A.; Dyshlyuk, L.; Ivanova, S. Identification and quantification of phenolic compounds of Western Siberia Astragalus danicus in different regions. Heliyon 2019, 5, e02245. [CrossRef]

25. Li, M.; Xu, Y.; Yang, W.; Li, J.; Xu, X.; Zhang, X.; Chen, F.; Li, D. In vitro synergistic anti-oxidant activities of solvent-extracted fractions from Astragalus membranaceus and Glycyrrhiza uralensis. LWT 2011, 44, 1745-1751. [CrossRef]

26. Simons, R.; Vincken, J.P.; Bakx, E.J.; Verbruggen, M.A.; Gruppen, H. A rapid screening method for prenylated flavonoids with ultra-high-performance liquid chromatography/electrospray ionisation mass spectrometry in licorice root extracts. Rapid Commun. 2009, 23, 3083-3093. [CrossRef] [PubMed]

27. Frański, R.; Gierczyk, B.; Kozik, T.; Popenda, Ł.; Beszterda, M. Signals of diagnostic ions in the product ion spectra of [M-H] ${ }^{-}$ ions of methoxylated flavonoids. Rapid Commun. 2019, 33, 125-132. [CrossRef]

28. Zhao, X.; Zhang, S.; Liu, D.; Yang, M.; Wei, J. Analysis of flavonoids in dalbergia odorifera by ultra-performance liquid chromatography with tandem mass spectrometry. Molecules 2020, 25, 389. [CrossRef]

29. Yang, B.; Liu, H.; Yang, J.; Gupta, V.K.; Jiang, Y. New insights on bioactivities and biosynthesis of flavonoid glycosides. Trends Food Sci. Technol. 2018, 79, 116-124. [CrossRef]

30. March, R.E.; Lewars, E.G.; Stadey, C.J.; Miao, X.S.; Zhao, X.; Metcalfe, C.D. A comparison of flavonoid glycosides by electrospray tandem mass spectrometry. Int. J. Mass Spectrom. 2006, 248, 61-85. [CrossRef]

31. Schmidt, S.; Zietz, M.; Schreiner, M.; Rohn, S.; Kroh, L.W.; Krumbein, A. Identification of complex, naturally occurring flavonoid glycosides in kale (Brassica oleracea var. sabellica) by high-performance liquid chromatography diode-array detection/electrospray ionization multi-stage mass spectrometry. Rapid Commun. 2010, 24, 2009-2022. [CrossRef]

32. Vukics, V.; Guttman, A. Structural characterization of flavonoid glycosides by multi-stage mass spectrometry. Mass Spectrom. Rev. 2010, 29, 1-16. [CrossRef] [PubMed]

33. Stobiecki, M. Application of mass spectrometry for identification and structural studies of flavonoid glycosides. Phytochemistry 2000, 54, 237-256. [CrossRef]

34. Jin, X.; Lu, Y.; Chen, S.; Chen, D. UPLC-MS identification and anticomplement activity of the metabolites of Sophora tonkinensis flavonoids treated with human intestinal bacteria. J. Pharm. Biomed. 2020, 184, 113176. [CrossRef]

35. Huang, B.M.; Chen, T.B.; Xiao, S.Y.; Zha, Q.L.; Luo, P.; Wang, Y.P.; Cui, X.M.; Liu, L.; Zhou, H. A new approach for authentication of four ginseng herbs and their related products based on the simultaneous quantification of 19 ginseng saponins by UHPLCTOF/MS coupled with OPLS-DA. RSC Adv. 2017, 7, 46839-46851. [CrossRef]

36. Thaipong, K.; Boonprakob, U.; Crosby, K.; Cisneros Zevallos, L.; Byrne, D.H. Comparison of ABTS, DPPH, FRAP, and ORAC assays for estimating antioxidant activity from guava fruit extracts. J. Food Compost. Anal. 2006, 19, 669-675. [CrossRef]

37. Mensor, L.L.; Menezes, F.S.; Leitão, G.G.; Reis, A.S.; Santos, T.C.d.; Coube, C.S.; Leitão, S.G. Screening of Brazilian plant extracts for antioxidant activity by the use of DPPH free radical method. Phytother. Res. 2001, 15, 127-130. [CrossRef] [PubMed]

38. Sun, T.; Ho, C.T. Antioxidant activities of buckwheat extracts. Food Chem. 2005, 90, 743-749. [CrossRef]

39. Alam, M.N.; Bristi, N.J.; Rafiquzzaman, M. Review on in vivo and in vitro methods evaluation of antioxidant activity. Saudi Pharm J. 2013, 21, 143-152. [CrossRef]

40. Munteanu, I.G.; Apetrei, C. Analytical methods used in determining antioxidant activity: A Review. Int. J. Mol. Sci. 2021, 22, 3380. [CrossRef]

41. Valgimigli, L.; Amorati, R.; Petrucci, S.; Pedulli, G.F.; Hu, D.; Hanthorn, J.J.; Pratt, D.A. Unexpected acid catalysis in reactions of peroxyl radicals with phenols. Angew. Chem. 2009, 121, 8498-8501. [CrossRef]

42. Abir, C.; Minjie, Z.; Hassan, R.; Ennahar, S. Hyphenated LC-ABTS•+ and LC-DAD-HRMS for simultaneous analysis and identification of antioxidant compounds in Astragalus emarginatus Labill. extracts. J. Pharm. Biomed. Anal. 2021, $21,1-17$. [CrossRef]

43. Bratkov, V.M.; Shkondrov, A.M.; Zdraveva, P.K.; Krasteva, I.N. Flavonoids from the genus Astragalus: Phytochemistry and biological activity. Pharm. Rev. 2016, 10, 11.

44. Salehi, B.; Carneiro, J.N.P.; Rocha, J.E.; Coutinho, H.D.M.; Morais Braga, M.F.B.; Sharifi-Rad, J.; Semwal, P.; Painuli, S.; Moujir, L.M.; de Zarate Machado, V.J.P.R. Astragalus species: Insights on its chemical composition toward pharmacological applications. Phytother. Res. 2021, 35, 2445-2476. [CrossRef]

45. Yu, D.H.; Bao, Y.m.; Wei, C.L.; An, L.J. Studies of chemical constituents and their antioxidant activities from Astragalus mongholicus Bunge. Biomed. Environ. Sci. 2005, 18, 297. [PubMed]

46. Quéguineur, B.; Goya, L.; Ramos, S.; Martín, M.A.; Mateos, R.; Bravo, L. Phloroglucinol: Antioxidant properties and effects on cellular oxidative markers in human HepG2 cell line. Food Chem. Toxicol. 2012, 50, 2886-2893. [CrossRef] [PubMed]

47. Wang, H.; Guo, X.; Hu, X.; Li, T.; Fu, X.; Liu, R.H. Comparison of phytochemical profiles, antioxidant and cellular antioxidant activities of different varieties of blueberry (Vaccinium spp.). Food Chem. 2017, 217, 773-781. [CrossRef] 
48. López Alarcón, C.; Denicola, A. Evaluating the antioxidant capacity of natural products: A review on chemical and cellular-based assays. Anal. Chim. Acta 2013, 763, 1-10. [CrossRef]

49. Kaspar, J.W.; Niture, S.K.; Jaiswal, A.K. Nrf2: INrf2 (Keap1) signaling in oxidative stress. Free Radic. Biol. 2009, 47, 1304-1309. [CrossRef]

50. Liu, K.; Luo, M.; Wei, S. The bioprotective effects of polyphenols on metabolic syndrome against oxidative stress: Evidences and perspectives. Oxid. Med. Cell. Longev. 2019, 2019, 6713194. [CrossRef]

51. Yao, Y.; Wang, H.; Xu, F.; Zhang, Y.; Li, Z.; Ju, X.; Wang, L. Insoluble-bound polyphenols of adlay seed ameliorate H2O2-induced oxidative stress in HepG2 cells via Nrf2 signalling. Food Chem. 2020, 325, 126865. [CrossRef] [PubMed]

52. DeNicola, G.M.; Karreth, F.A.; Humpton, T.J.; Gopinathan, A.; Wei, C.; Frese, K.; Mangal, D.; Kenneth, H.Y.; Yeo, C.J.; Calhoun, E.S. Oncogene-induced Nrf2 transcription promotes ROS detoxification and tumorigenesis. Nature 2011, 475, 106-109. [CrossRef] [PubMed]

53. Chen, J.; Yang, J.; Ma, L.; Li, J.; Shahzad, N.; Kim, C.K. Structure-antioxidant activity relationship of methoxy, phenolic hydroxyl, and carboxylic acid groups of phenolic acids. Sci. Rep. 2020, 10, 2611. [CrossRef] [PubMed]

54. Alzand, K.I.; Mohamed, M.A. Flavonoids: Chemistry, biochemistry and antioxidant activity. J. Pharm. Res. 2012, 5, 4013-4020. 